ORIGINAL ARTICLE

\title{
Novel Identification of Group B Streptococcus and Enterobacter sakazakii in Infant Suspected to Septicemia
}

\section{Farzan Modaresi $^{\mathbf{1}, 2,3 *}$, Arash Hasannezhad ${ }^{1,4}$, Zahra Rezaei $^{1,4}$, Akbar Kazemi ${ }^{2}$ \\ ${ }^{1}$ Central laboratory Research, Jahrom University of Medical Sciences, Jahrom, Iran \\ ${ }^{2}$ Department of Microbiology, School of Medicine, Jahrom University of Medical Sciences, Jahrom, Iran \\ ${ }^{3}$ Department of Advanced Medical Sciences and Technology, Jahrom University of Medical Sciences, Jahrom, Iran \\ ${ }^{4}$ Student Research Committee, Jahrom University of Medical Sciences, Jahrom, Iran}

Study Area:Jahrom, Iran

Coordinates: $28^{\circ} 30^{\prime} \mathrm{oo}^{\prime \prime} \mathrm{N} ; 53^{\circ} 33^{\prime} 38^{\prime \prime} \mathrm{E}$

Keywords: GBS, Multiplex-real time PCR

This project was approved by the Jahrom University of Medical Sciences with Ethical Code Number: IR.JUMS.REC.1397.009

\section{Abstract}

Group B Streptococcus (GBS) is a major pathogen in neonates and pregnant women. Infant infections are signif icantly associated with maternal vaginal colonization with GBS during pregnancy. Enterobacter sakazakii is potentially a harmful bacterium, widely found in nature, transmitted from infected milk powder to infants causes various diseases. One of the biggest problems of these bacteria is the development of septicemia in newborns, causes fever, increased heart rate, respiration, and confusion. In this study, 200 blood samples were collected from infant suspected to septicemia. The bacterial genome content was then extracted by Fermehtas kits. By using the Multiplex-real time PCR technique, Group B Streptococcus \& Enterobacter sakazakii were identified and their levels were determined. A total of 16 neonates (8\%) with Enterobacter sakazakii infection andio infants (5\%) with GBS infection were observed. Revealing the negative result of blood cultures in the current study, molecular level studies also suggested by involving other parts of the infants' body.

pregnancy and the transmission of bacteria to the baby occurs through ascites into the amniotic fluid or when passing through the delivery tube (Dhanoa et al., 2010). GBS can cause infections like septicemia, meningitis, cellulitis, adenitis, conjunctivitis, pneumonia, and otitis in newborns, including sepsis and meningitis, and high mortality despite antibiotic therapy (Amirmozafari et al., 2006). According to McGregor (2000), all pregnant women should perform early diagnosis of bacterial vaginosis in the first weeks of pregnancy. Leitich et al. (2003) showed that bacterial vaginosis is a risk factor for early labor and abortion. The prevalence of bacterial vaginosis varies widely among ethnic groups and geographical locations (Campbell et al., 2000; Tolosa et al., 2006) so it is suggested that their relationship with preterm labor must be investigated separately for each country (Goffinet et al., 2003).

A prevalence of GBS was reported in some countries belonging to different geographical regions, with $22 \%$ in the Middle East and North Africa, 19\% in Asia and the Pacific, 19\% in Sub-Saharan Africa, 14\% in the Americas and $12 \%$ in India and Pakistan (Stoll \& Schuchat , 1998). Epidemiologic studies also showed that the colonization of 
GBS among Iranian women ranged from $1.9 \%$ to $26.7 \%$ (Fatemi et al., 2010; Rabiee et al., 2015).

Enterobacter sakazakii is a gram negative, negative oxidase, positive catalase, anaerobic, spores free from Entero-bacteriaceae family, which is widely found on the nature and intestinal tract of humans and animals (Farmer et al., 1980). It is a potentially harmful bacterium that is transmitted from infected milk to infants and due to various diseases, including meningitis, brain abscesses, necrotizing enterocolitis, encephalitis, meningococcal necrosis encephalitis, bacteremia and sepsis in newborns, especially premature newborns. Babies with suppressed immune systems, as well as low birth-weight infants, have been reported by Dumen (2010). Although there is no evidence of an epidemiological association with the infectious dose of this bacterium, the approximate number is about 1,00o organisms, which is very low and is similar to the infectious dose of pathogenic bacteria such as Listeria monocytogenes, Escherichia coli O157, and Neisseria meningitides (Baumgartner et al., 2009; Iverse et al., 2003). As stated, this pathogenic bacterium is an opportunistic and potentially pathogenic, especially in infants, the most commonly reported illnesses to occur in infants below the age of 12 months, especially preterm infants, birth def icient infants and suppressed immune neonates (MRAS-6, 2004). It is because this group of individuals is more susceptible to bacterial sepsis due to gram-negative and endotoxin bacteria associated with necrotizing enterocolitis (BeckSague et al., 1994; Stoll et al., 2004). In many cases, the importance of diseases caused by this organism is ignored due to the lack of proper sampling and the lack of advanced diagnostic facilities in clinical laboratories and the persistence of infection by Enterobacter sakazakii by physicians. Furthermore, in our country there are no clinical laboratories in hospitals is available for automatic culture systems, and the blood culture is carried out only through the traditional culture method. Thus the chances for proper identification and isolation of this organism are greatly reduced (CDCP, 2002). One of the biggest dangers of these bacteria is the development of septicemia in newborns, which itself create problems like fever, increased heart rate, increased breathing, confusion. There are also other symptoms that are associated with certain infections such as coughing with pneumonia or urinating with pain and kidney infection.

\section{Methodology:}

For this study, blood samples were collected from 200 infants below the age group of 12 months who were suspected of septicemia, admitted in hospitals of Shiraz and Jahrom for one year. We isolated the blood samples using $3000 \mathrm{rpm}$, then, using a sterile loop, we cultivate the whole blood on MacConkey Agar medium and incubated for 24 hour in $37^{\circ} \mathrm{C}$. Further, using the Fermentans kit, the genome content of the bacteria grown on the medium was extracted following the kit protocol. As a positive control of DNA, the purified genomes of GBS and E.sakazakii were prepared from the reference laboratory. Then, using the real-time method, the bacterial presence was determined in the specimens.

Extraction of DNA from blood: $200 \mu \mathrm{L}$ of whole blood was extracted by the Fermentas DNA blood mini kit within a week of sample collection. Extracted DNA was frozen at $80^{\circ} \mathrm{C}$ until it underwent Real time PCR.

Primer design: based on the GBS sequences in GenBank, one pairs of primers were designed with PRI-MER3.o (http://frodo.wi.mit.edu/primer3), Primer Explorer (http://primerexplorer.jp/e/) and NCBI primer-Blast tools (http://www.ncbi.nlm.-nih.gov/tools/primer-blast). Primers were synthesized commercially at Geneary Co. Ltd. (China). The primer $16 \mathrm{~S}-23 \mathrm{~S}$ rRNA inter-genics spacer region (ISR), within the GBS genome (Table 1).

\begin{tabular}{lll} 
& \multicolumn{2}{c}{ Table 1. primers: Gene bank: FJ555494 } \\
\hline Bacteria & \multicolumn{1}{c}{ Forward } & \multicolumn{1}{c}{ Primers } \\
& \multicolumn{1}{c}{ Reverse } \\
\hline GBS & IGS-1, GGAAACCTG & IGS-2,AATCTATTTCT \\
& CCATTTGCGTCT & AGATCGTGGAAT \\
E.sakazakii & ESOMP5- F: 5'- & ESOMP5-R: 5' \\
& GGTGAAGGATTTA & GCGCCTCGTTATCA \\
& ACCGTGAACTT-3 & TCCAAA-3'
\end{tabular}

Real time PCR: the PCR mixture $(20 \mu \mathrm{L})$ contained $10 \mu \mathrm{L}$ of 2 X SYBR Green Real-time PCR master mix (Ampliquon, Denmark), $0.5 \mu \mathrm{M}$ of each specific primer and $1 \mu \mathrm{L}$ of template DNA. The PCR was performed in an $\mathrm{AB}$ real-time $\mathrm{RCR}$ thermal cycler with the following program; $94^{\circ} \mathrm{C}$ for 1 min, 40 cycles of amplification $\left(94^{\circ} \mathrm{C}\right.$ for $30 \mathrm{~s}, 55^{\circ} \mathrm{C}$ for $30 \mathrm{~s}$ and $72^{\circ} \mathrm{C}$ for $20 \mathrm{~s}$ ), followed by a final 10-min extension at $72^{\circ} \mathrm{C}$. The $\mathrm{qPCR}$ run was done in triplicate for each assay.

\section{Results:}

In our study, Novel identification was done by using multiplex-realtime PCR on 200 suspected septicemia neonates, using primers

GBS:

"IGS-1 GGAAACCTGCCATTTGCGTCT" \& "IGS-2 AATCTATTTCTAGATCGTGGAAT"

Entrobacter sakazakii:

ESOMP 5-F: 5'GGTGAAGGATTTAACCGTGAACTT-3 \& ESOMP5-R: 5'-GCGCCTCGTTATCATCCAAA-3'

Total 16 infants from 200 (8\%) with Enterobacter sakazakii infection and 10 infants from 200 (5\%)with GBS infection were observed.

\section{Discussion:}

As mentioned earlier, Enterobacter sakazakii and GBS are two significant types of opportunistic pathogens for neonatal infections and can also cause various diseases in infants and sometimes cause death (Farmer et al., 1980; 


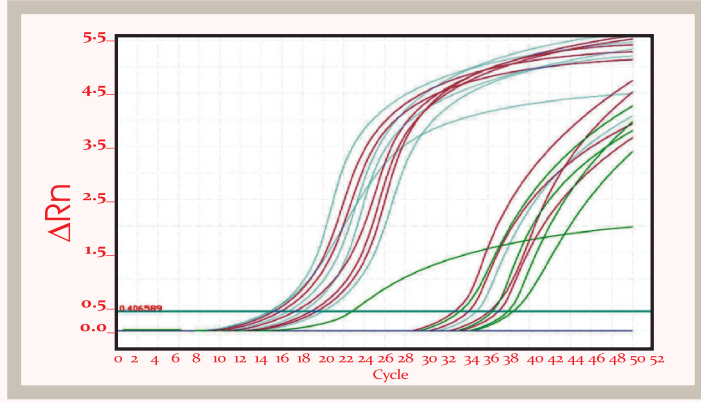

Figure 1. Amplification of GBS strains. The experiment performed as triplicate

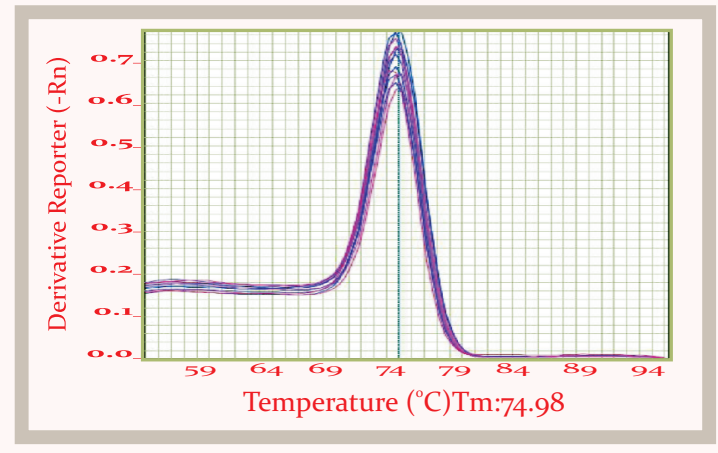

Figure-2:2. melting curve for GBS primers

Palmeiro etal., 2010; Madzivhandila et al., 2011).

This study on the prevalence of E.sakazakii and GBS infections was important for searching prevention possibilities towards epidemics and in reducing infant mortality. Timely diagnosis and treatment of pregnant mothers to prevent fatal infections can be considered as one of the most important issues in the study of the prevalence of GBS infection.

As stated earlier, E.sakazakii is an infected milk formula infection that can be a contributing factor to the country's food and drug systems (Dumen, 2010). Khadijeh et al. (2013) reported on a basis of a molecular study, conducted on infants with sepsis to detect E.sakazakii, the infection rate was $0 \%$, but blood culture in $1.4 \%$ of the samples was positive for Streptococcus agalactiae (GBS). Anthony \& Okada (1977) in their study on the emergence of GBS on newborn babies in American and British hospitals reported that the incidence of this infection in neonates was between 1.3 and 3 per 1,0oo live births. In a study by Behjati (1998) conducted on 114 children of below the age of 28 days, diagnosed with septicemia, found positive cultures, and some of them had multiple infections. There were 128 various bacteria and 13 of them (10.5\%) were E.sakazakii. On the basis of a molecular study of epidemiology of betahemolytic GBS, colonized in the reproductive system of pregnant women, Kazem et al. (2011) reported that vaginal and rectal cultures of 21 women out of $250(8.4 \%)$ and in the PCR assay, the colonization of GBS 24 out of 250 (9.6\%) pregnant women were positive.

In our study, using Real-time PCR, we examined simultaneously 2 important pathogens of E.sakazakii and GBS in susceptible septicemia neonates in Shiraz and Jahrom. Results showed that these bacteria were still potentially causing an epidemic in Fars province.

\section{Acknowledgment:}

We are thankful to all such parents and guardians of the particinats who had allowed us to carried out this study on their infant. We also thankful to the other medical staffs for helping us invarious ways to conduct this study

\section{References:}

Ahmadi, K., Sheikh, A.F., Mardaneh, J., Modarresi, F. \& Shoja, S. (2013): Detection of Enterobacter sakazakii in neonatal sepsis by PCR on $16 \mathrm{~S}$ ribosomal RNA. Iranian South Med. I., 7(3):272-9.

Amirmozafari, N., Ghanaei, M.M., Nouri, B. \& Tooli, L.F. (2006): Survey prevalence of Group B Streptococci in genital tract women in 28-37 weeks pregnancy. L. Guilan Univ. Med. Sci., 15(59):91-96.

Anthony, B.F. \& Okada, D.M. (1977): The emergence of group B streptococci in infections of the newborn infant. Annu. Rev. Med., 28:355-369.

Baumgartner, A., Grand, M., Liniger, M. \& Iversen, C. (2009): Detection and frequency of Cronobacter spp. (Enterobacter sakazakii) in different categories of ready-to-eat foods other than infant formula. Int. J. Food Microbiol., 136(2):189-192.

Beck-Sague, C.M., Azimi, P., Fonseca, S.N., Baltimore, R.S., Powell, D.A., Bland, L.A., Arduino, M.J., McAllister, S.K., Huberman, R.S. \& Sinkowitz, R.L.(1994): Bloodstream infections in neonatal intensive care unit patients: results of a multicenter study. Pediatr. Infect. Dis. J., 13(12):1110-1116.

Behjati, S. (1998): Reporting of antimicrobial susceptibility and microorganisms in neonatal sepsis in children medical center hospital. Tehran Univ. Med.J., 56(2):22-24.

Campbell, J.R., Hillier, S.L., Krohn, M.A., Ferrieri, P., Zaleznik, D.F. \& Baker, C.J. (200o): Group B streptococcal colonization and serotype-specific immunity in pregnant women at delivery. Obstet. Gynecol., 96(4):498-503.

CDCP (Centers for Disease Control and Prevention) (2002): Enterobacter sakazakii Infections Associated with the Use of Powdered Infant Formula-Tennessee, 2001, MMWR. 51(14):297-300

Convert, M., Martinetti Lucchini, G., Dolina, M., \& Piffaretti, J.C. (2005): Comparison of lightcycler PCR and culture for detection of group B streptococci from vaginal swabs. Clin. Microbiol. Iinfect., 11(12):1022-1026

Dhanoa, A., Karunakaran, R. \& Puthucheary, S. (2010): Serotype distribution and antibiotic susceptibility of group B streptococci in pregnant women. Epidemiol. Infect., 138(7):979-981.

Dumen, E. (2010): Cronobacter sakazakii (Enterobacter sakazakii): only an infant problem. Kafkas Univ. Vet. Fak. Derg., 16(Suppl-A):S171-S178.

Farmer, J.J.III, Asbury, M.A., Hickman, F.W., Brenner, D.J. \& The Enterobacteriaceae Study (1980): Enterobacter sakazakii: a new species of "Enterobacteriaceae" isolated from clinical specimens. Int. J. Sys. Evol. Microbiol., 30(3):569-584. 
Fatemi, F., Pakzad, P., Zeraati, H., Talebi, S., Asgari, S., Akhondi, M.M. \& Tabriz, L.C. (2010): Comparative molecular and microbiologic diagnosis of vaginal colonization by group $\mathrm{B}$ streptococcus in pregnant women during Labor. Iranian J. Basic Med.Sci., 13(4):183-188.

Goffinet, F., Maillard, F., Mihoubi, N., Kayem, G., Papiernik, E., Cabrol, D. \& Paul, G. (2003): Bacterial vaginosis: prevalence and predictive value for premature delivery and neonatal infection in women with preterm labour and intact membranes. Eur.J. Obstet. Gynecol. Reprod. Biol., 108(2):146-151.

Iversen, C. \& Forsythe, S. (2003): Risk profile of Enterobacter sakazakii, an emergent pathogen associated with infant milk formula. Trends Food Sci. Technol., 14(11):443-454.

Leitich, H., Bodner-Adler, B., Brunbauer, M., Kaider, A., Egarter, C. \& Husslein, P. (2003): Bacterial vaginosis as a risk factor for preterm delivery: a meta-analysis. Am. J. Obstet. Gynecol., 189(1):139-147.

Madzivhandila, M., Adrian, P.V., Cutland, C.L., Kuwanda, L., Schrag, S.J. \& Madhi, S.A. (2011): Serotype distribution and invasive potential of group B streptococcus isolates causing disease in infants and colonizing maternal-newborn dyads. PloSone, 6(3):e17861.

McGregor, J.A. \& French, J.I. (2000): Bacterial vaginosis in pregnancy. Obstet. Gynecol. Surv., 55(5Suppl.1):1-19.

Kazem, S.Y.M., Ronak, B., Golnaz, M., Mahdi, S.D.M. \& Bagher, K.M. (2011): Study of molecular epidemiologic of group b streptococcus colonization in pregnant women by PCR method. Payavard-Salamat, 5(2):51-59.

MRAS-6 (Microbiological Risk Assessment Series-6) (2004): Enterobacter sakazakii and other microorganisms in powdered infant formula: Meeting Report. Pub. by: World Health Organization Food And Agriculture Organization Of The United Nations. 8o p.

Palmeiro, J.K., Dalla-Costa, L.M., Fracalanzza, S.E., Botelho, A.C., da Silva Nogueira, K., Scheffer, M.C.,Torres, R.S.L.A, Carvalho, N.S., Cogo, L.L. \& Madeira, H.M.F. (2010): Phenotypic and genotypic characterization of group B streptococcal isolates in southern Brazil.J. Clin. Microbiol., 48(12):4397-4403.
Rabiee, S., Arab, M. \& Mashouf, R.Y. (2015): Epidemiologic pattern of vaginal colonization by group B Streptococcus in pregnant women in Hamadan, Central west of Iran. Iranian J. Med. Sci., 31(2):106-108.

Stoll, B.J., Hansen, N., Fanaroff, A.A. \& Lemons, J.A. (2004): Enterobacter sakazakii is a rare cause of neonatal septicemia or meningitis in VLBW infants. J. Pediatr., 144(6):821-823

Stoll, B.J. \& Schuchat, A. (1998): Maternal carriage of group B streptococci in developing countries. Pediatr. Infect. Dis. J., $17(6): 499-503$.

Tolosa, J.E., Chaithongwongwatthana, S., Daly, S., Maw, W.W., Gaitán, H., Lumbiganon, P., Festin, M., Chipato, P., Sauvarin, J., Goldenberg, R.L., Andrews, W.W. \& Whitney, C.G. (2006): The International Infections in Pregnancy (IIP) study: variations in the prevalence of bacterial vaginosis and distribution of morphotypes in vaginal smears among pregnant women. Am. J. Obstet. Gynecol., 195(5):1198-1204.

Turner, C., Turner, P., Po, L., Maner, N., De Zoysa, A., Afshar, B., Efstratiou, A., Heath, P.T. \& Nosten, F. (2012): Group B streptococcal carriage, serotype distribution and antibiotic susceptibilities in pregnant women at the time of delivery in a refugee population on the Thai-Myanmar border. $\underline{B M C \text { Infect. }}$ Dis., 12(1):34

Ulett, K.B., Benjamin, W.H., Zhuo, F., Xiao, M., Kong, F., Gilbert, G.L., Schembri, M.A. \& Ulett, G.C. (2009): Diversity of group B streptococcus serotypes causing urinary tract infection in adults. J. Clin. Microbiol., 47(7):2055-206o.

Valkenburg-van den Berg, A.W., Sprij, A.J., Oostvogel, P.M., Mutsaers, J.A., Renes, W.B., Rosendaal, F.R. \& Joep Dörr P. (2006): Prevalence of colonisation with group B Streptococci in pregnant women of a multi-ethnic population in The Netherlands. Eur. J. Obstet. Gynecol. Reprod. Biol., 124(2):178183.

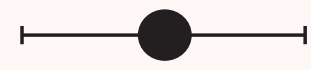

